\title{
BENTUK LAGU DAN AMBITUS NADA PADA ORKESTRASI MARS UNESA
}

\author{
Harpang Yudha Karyawanto \\ Program Studi Seni Musik Fakultas Bahasa dan Seni Universitas Negeri Surabaya \\ Emai: harpangkaryawanto@unesa.ac.id
}

\begin{abstract}
Universities in Indonesia have different characters that excel in various fields, one of which provides the icon is mars songs in a higher education institution. Mars songs have a summary of meanings that reflect an institution, both internal and external. Not only at universities, other institutions, such as public and private schools, Korpi, cooperatives, Dharma Wanita, and also groups / parties to companies and others also have marching songs. This proves that Mars strongly contributes to an advanced institution that has quality and encouragement of improvement into the future. This research provides an alternative in analyzing a march song. The method used is the Form of Music Analysis Science. This paper describes the results of the analysis of song forms and tone of ambition in the Mars Unesa orchestration.
\end{abstract}

Key Words: Orchestration, Song Forms, Mars Songs

\begin{abstract}
Abstrak: Perguruan Tinggi di Indonesia mempunyai karakter berbeda-beda yang unggul diberbagai bidang, salah satu yang memberikan icon tersebut adalah lagu mars dalam sebuah lembaga pendidikan tinggi. Lagu mars mempunyai ringkasan makna yang mencerminkan suatu lembaga, baik internal maupun eksternal. Tidak hanya pada Perguruan Tinggi saja, lembaga-lembaga lainnya, seperti Sekolah negeri maupun swasta, Korpi, Koperasi, Dharma Wanita, dan juga Golongan/Partai sampai perusahasan maupun yang lain juga mempunyai lagu mars. Hal tersebut membuktikan bahwa mars sangat memberikan konstribusi terhadap suatu lembaga maju yang memiliki kualitas dan dorongan peningkatan ke masa depan. Penelitian ini memberikan alternative dalam menganalisis sebuah lagu mars. Metode yang digunakan yaitu Ilmu Bentuk Analisis Musik. artikel ini memaparkan hasil analisis bentuk lagu dan ambitus nada pada orkestrasi Mars Unesa.
\end{abstract}

Kata kunci: Orkestrasi, Bentuk Lagu, Lagu Mars

\section{PENDAHULUAN}

Musik mars atau lagu mars adalah komposisi musik dengan irama teratur dan kuat. Musik jenis ini secara khusus diciptakan untuk meningkatkan keteraturan dalam berbaris sebuah kelompok besar, terutama barisan tentara, dan paling sering dimainkan oleh korps musik militer. Lagu mars dapat ditulis dalam birama genap $2 / 4,4 / 4$, tetapi kadang-kadang dalam birama $6 / 8$, atau 2 (genap) $\times 3 / 8$ dengan tempo cepat, (Simanungkalit, 2008:77-78 ). Perguruan Tinggi di Indonesia mempunyai karakter berbeda-beda yang unggul diberbagai bidang, salah satu yang memberikan icon tersebut adalah lagu mars dalam sebuah lembaga pendidikan tinggi. Lagu mars mempunyai ringkasan makna yang mencerminkan suatu lembaga, baik internal maupun eksternal. Tidak hanya pada Perguruan Tinggi saja, lembaga-lembaga lainnya, seperti Sekolah negeri maupun swasta, Korpi, Koperasi, Dharma Wanita, dan juga Golongan/Partai sampai perusahasan maupun yang lain juga mempunyai lagu mars. Hal tersebut membuktikan bahwa mars sangat memberikan konstribusi terhadap suatu lembaga maju yang memiliki kualitas dan dorongan peningkatan ke masa depan.

Universitas Negeri Surabaya (UNESA) merupakan salah satu Perguruan Tinggi Negeri di wilayah Indonesia Timur yang memiliki karakter keguruan yang masih melekat dalam instansi tersebut, dikarenakan Unesa merupakan eks-IKIP pada awal berdirinya. Sejarah serta visi dan misi tersebut menjadi landasan dari sebuah penciptaan lagu Mars, yang sampai sekarang dikenal dengan judul "Mar UNESA".

Lagu Mars UNESA dibuat melalui lomba penciptaan Hymne dan Mars Universitas Negeri Surabaya (UNESA) pada 
tahun 1999 yang diselenggarakan oleh Lembaga Penelitian Universitas Negeri Surabaya dan dibuka untuk umum. Setelah melalui seleksi yang cukup ketat maka Lagu Mars UNESA karya Heni Kusumawati tersebut dinyatakan sebagai pemenang I Lomba Cipta lagu Mars Universitas Negeri Surabaya terhitung sejak tanggal 1 Desember 1999. Karya lagu mars UNESA terdiri dari 24 birama dan termasuk dalam lagu bentuk 2 bagian. Lagu tersebut mengacu pada prinsip mars moderen dimana tidak setiap pukulan/ketukan/beat mengandung nilai nada bermotif 3/16 bersambung dengan 1/16-an. Mars Unesa termasuk dalam katagori mars modern. Hasil cipta lagu mars tersebut sudah diolah atau diaransemen dengan konsep musik mars yang lebih identik dengan marching band. Pada penelitian ini, lagu mars akan diorkestrasi dengan konsep musik orkestra, dengan harapan mars ini dapat disuguhkan dalam acara didalam gedung/indoor, seperti halnya dalam acara Prosesi Wisuda, Konferensi, Pengukuhan Guru Besar, dan sebagainya.

Orkestrasi adalah suatu kegiatan yang berkait erat dengan penulisan sebuah orkestra atau penulisan ke dalam bentuk berbagai ansambel. Aktivitas seperti ini lazimnya diilhami (the imagine), oleh karya musik yang tertulis (music score) atau karena karya musik yang didengar (music audio). Meskipun kegiatan orkestrasi tidak sesulit membuat karya aransemen namun juga bukan pekerjaan yang sepele, karena orkestrator tidak hanya sekedar faham tentang teori musik yang sederhana melainkan harus pula mempunyai kecenderungan kepada basic harmoni yang baik dan memadahi. Orkestrasi pada prakteknya mempunyai 2 (dua) cara pendekatan : (1) Transcription, memindahkan tulisan kedalam formasi lain tanpa mengadakan perubahan sedikitpun dari score aslinya baik melodi maupun harmoninya (original); (2) Arrangement, menulis kembali kedalam formasi lain dengan mengadakan perubahan yang mencolok (significant), diberbagai aspek dari score aslinya, tanpa merubah melodi pokok (cantus fermus) nya. Pada proses orkestrasi lagu mars Unesa dilakukan menjadi dua tahap, yaitu seperti bahasan di atas. Dengan harapakan hasil orkestrasi ini dapat memberikan warna lain dalam mewujudkan kampus Negeri yang modern dan inovatif.

Aransemen adalah pengadaptasian satu medium musik yang asli, menjadi medium yang berbeda (Scholes 1938 : 53). Pelaku aransemen atau orang yang mengaransemen suatu karya musik disebut arranger. Aransemen merupakan suatu kegiatan dalam musik yang menuntut pelaku aransemen (arranger) dalam mengembangkan ide terhadap suatu karya musik dan kreatifitas dari seorang arranger dibutuhkan dalam mengembangkan ide tersebut. Bentuk ide/kreatifitas dapat diperoleh melalui imajinasi seorang arranger untuk menyusun konsep awal dalam sebuah aransemen musik. Sebuah karya musik yang diciptakan seorang komposer, maupun sebuah karya musik yang sudah diaransemen oleh seorang arranger, mempunyai fungsi sebagai sarana hiburan maupun pendidikan. Fungsi musik sebagai sarana hiburan maupun pendidikan, tidak terlepas dari peran seorang komposer maupun arranger dalam menyampaikan ide musikalnya. Dalam proses orkestrasi terdapat proses aransemen, dimana harus mengubah dan mengembangkan motid lagu, ritme serta harmoni, sehingga menghasilkan suatu orkestrasi yang indah dan megah.

\section{METODE ANALISIS}

Metode penelitian pada dasarnya merupakan cara ilmiah untuk mendapatkan data dengan tujuan dan kegunaan tertentu. (Sugiyono, 2013:3). deskriptif analisis merupakan suatu metode penelitian yang mengungkapkan tentang obyek dalam bentuk deskriptif yang disertai analisis terhadap segala sesuatu melalui pendekatan yang telah ditentukan. Dalam hal ini pendekatan etnomusikologis pendekatan ini tidak hanya terbatas pada musiknya akan tetapi mencakup seluruh aspek budaya yang ada kaitannya dengan musik (Nettl 1964:132).

Bentuk penelitian ini Analisis Musik. Menganalisis musik berarti menguraikan komponen-komponen pembentuk musik tersebut. Komponen di sini bisa diartikan sebagai unsur pembentuk musik. Aaron Coplan (1939:33) mengungkapkan bahwa unsur-unsur musik meliputi: melodi, ritme, harmoni, dan timbre (warna bunyi)". Mentranskripsikan unsur-unsur musik pada dasarnya adalah mengalihkan unsur-unsur 
tersebut dari bentuk audio ke dalam bentuk visual atau tulisan". Hal ini sejalan dengan pengertian penotasian dalam etnomusikologi, yaitu "proses mengalihkan bunyi menjadi simbol visual". Tata kerja transkripsi dua cara pendekatan yang penting, yaitu membuat analisis serta mendeskripsikan apa yang kita dengar dan menuliskannya di atas kertas (tentang musik yang didengar) dan mendeskripsikan apa yang kita lihat, Nettle (1964:98)

\section{PEMBAHASAN}

\section{Analisis lagu}

Pada lagu Mars Unesa terdapat dua kelompok (periode) lagu yang memiliki 16 birama yang terbagi dalam dua kelompok, yaitu A dan B. Masing-masing kelompok terdiri dari 8 birama, maka kedua kelompok A dan B terdiri dari 16 birama. Setiap kelompok tersusun atas frase tanya dan jawab. Setengah kelompok pertama disebut kalimat tanya (antecedent) dan kelompok kedua kalimat jawab (consequent).

Pada kelompok A, 4 birama pertama sebagai frase tanya dan 4 birama yang lain sebagai frase jawab. Dengan demikian apabila kelompok A ditulis dengan kode, menjadi A (aa').

Kode a sebagai frase tanya, sedangkan a' sebagai frase jawab. Frase a' merupakan pengulangan inti melodi utama yang seharusnya menjadi satu rangkaian dari kalimat tanya yang divariasi yang bermacammacam, di antaranya pengembangan ritme dan melodi pada peralihan nada pada sebuah frase. Pada lagu Mars Unesa ini setiap awal kalimat selalu diawali dengan birama gantung atau birama sebelum nada awal ketukan pertama. Hal tersebut dapat dilihat pada ilustrasi 5.1 di bawah ini :

\section{Kelompok A}

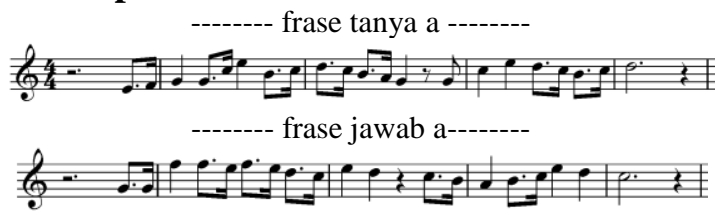

\section{Kelompok B}

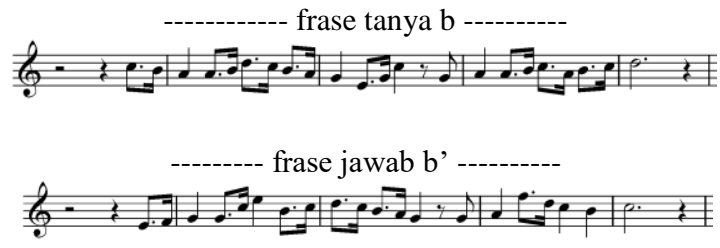

Ilustrasi 5.1

Bentuk Lagu Mars Unesa

Kelompok B apabila ditulis dengan kode ialah B (bb'). B sebagai frase tanya dan b' sebagai frase jawab. Frase b' juga merupakan satu kesatuan dari frase $b$ dengan ritme yang sangat berbeda, padahal secara teori merupakan sebuah bagian tersendiri. Pengembangan variasinya sangat kompleks, mulai dari ritme, serta alur melodi berbeda dalam setiap bagiannya.

b. Analisis Motif Lagu

Frase-frase yang terdapat pada tembang tersebut terbentuk dari dua semi frase yang berupa motif. Motif $X$ pada kelompok A, dan motif Y pada kelompok B. Hal ini dapat dilihat pada ilustrasi di bawah ini :

\section{KELOMPOK A}

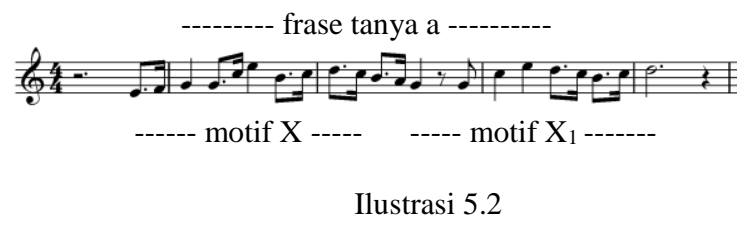

Motif X adalah motif pokok pada keseluruhan lagu dari kelompok A. Sedangkan $X_{1}$ adalah pengulangan motif $X$ yang berkaitan dalam satuan rangkaian melodi yang terdapat penyempitan ritme pada awal motif, serta penggandaan ritme dan motif awal dimulai dengan birama gantung, seperti tampak pada ilustrasi 5.2.

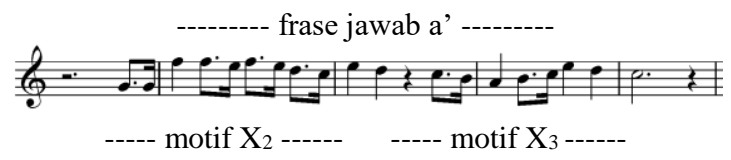

Ilustrasi 5.3

Pada frase a' terdapat dua motif, yakni motif $X_{2}$ dan motif $X_{3}$. Motif $X_{2}$ pada frase a' berbeda dengan motif $X$ pada frase $a$, karena terdapat perbedaan pola ritme, namun pada intinya sama pada pengembangan nadanya. Motif $\mathrm{X}$ pada frase a, dimulai dengan birama gantung, sedangkan $\mathrm{X}_{2}$ 
menerukan akhiran kalimat bagian pertama pada lagu Mars Unesa.

Motif $\mathrm{X}_{3}$ memiliki perbedaan dalam motif. Pada motif $\mathrm{X}_{3}$ terjadi Pelebaran ritme dari motif $\mathrm{X}_{2}$ pada akhir awal motif, seperti terlihat pada ilustrasi di atas. Motif $\mathrm{X}_{2}$ awal ritme terdapat not seperempat, sedangkan motif $\mathrm{X}_{3}$ terdapat not penuh. Pada kalimat ini merupakan penegasan jawaban dari kalimat tanya akhiran pada bagian lagu pertama Mars Unesa.

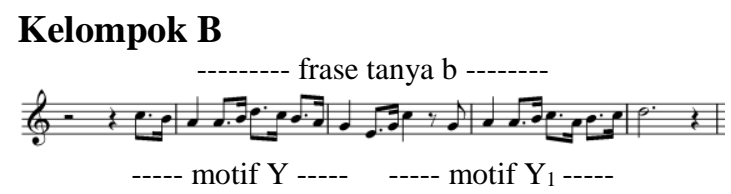

Ilustrasi 5.4

Pada kelompok B, frase $\mathrm{b}$ terdapat dua motif yaitu motif $Y$ dan motif $Y_{1}$. Motif Y merupakan motif pokok dari kelompok B. $\mathrm{Y}_{1}$ adalah rangkaian motif $\mathrm{Y}$ yang berbeda alur nada serta juga berbeda motif ritmenya. Motif $Y_{1}$ merupakan penghubung dari motif $\mathrm{Y}$ dengan selisih nada dan ritme yang berbeda sebagai penghantar pada kalimat berikutnya dengan variasi tingkat inteval, seperti yang tampak pada ilustrasi 5.4.

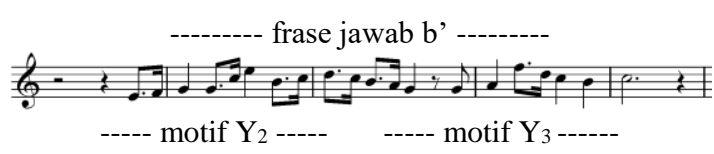

Ilustrasi 5.5

Pada frase b' terdapat dua motif, yakni motif $Y_{2}$ dan motif $Y_{3}$. Motif $Y_{2}$ pada frase b' sama dengan motif $Y$ pada frase $b$. motif $\mathrm{Y}_{3}$ memiliki perbedaan dalam pengolahan motif. Pada motif $\mathrm{Y}_{3}$ terjadi pelebaran ritme dari motif $\mathrm{Y}_{3}$, pada motif ini merupakan akhir dari kalimat lagu, seperti terlihat pada ilustrasi 5 .

\section{Ambitus Nada Pada Orkestrasi Lagu Mars UNESA}

Penerapan orkestrasi pada lagu "Mars

Unesa " terdapat pada setiap kalimat dalam bagian kompleksnya. Dalam penerapan orkestrasi akan dibahas mengenai orkestrasi dari melodi utama dan fungsi setiap instrumen. Berikut ini adalah penjelasannya.
Dalam hal ini yangmemainkan melodi utama yakni dimainkan secara bergantian bertautan antara instrument satu dengan yang lain dan nantinya string section beserta instrumen yang lain berfungsi sebagai pengiring, begitu pula sebaliknya.

Fullscore lagu Mars Unesa terdapat 17 instrumen yang terdiri dari : Tiup kayu atau woodwind (flute, oboe, clarinet), tiup logam atau brass (trumpet, trombone, horn, alto saxophone, tenor saxophone), gesek atau string (violin, viola, cello, contrabass), perkusi atau percussion (snare, cymbal), dan piano. Pada hakekatnya setiap instrumen tersebut mempunyai karakter, ambitus, teknik yang berbeda-beda. Hal tersebut yang membuat bentuk orkestrasi musik yang beragam dan seragam, berikut merupakan potongan fullscore orkestrasi lagu Mars Unesa.

Pada bab ini akan dijelaskan hasil analisis ambitus setiap instrument yang digunakan pada orkestrasi lagu Mars Unesa, yaitu : Tiup kayu atau woodwind (flute, oboe, clarinet), tiup logam atau brass (trumpet, trombone, horn, alto saxophone, tenor saxophone), gesek atau string (violin, viola, cello, contrabass).

\section{Ambitus Flute}

Pada aransemen lagu ini flute berperan sebagai melodi dan penghias nadanada yang tinggi. Instrumen ini mempunyai karakter yang lincah dan lebih mendominasi suara yang tinggi. Timbre flute sangat khas dengan suara kayunya sangat natural, sehingga mudah jika digabungkan dengan instrument gesek atau tiup kayu sejenisnya, bahkan dengan instrumen yang lain. Pada orkestrasi lagu Mars Unesa, nada tertinggi flute yaitu nada $G$ garis bantu 4, dengan teknik akhir trill yang terdapat pada birama 9 . Nada terendah flute yaitu $G$ middle terdapat pada birama 15. Dapat dilihat pada ilustrasi di bawah ini :

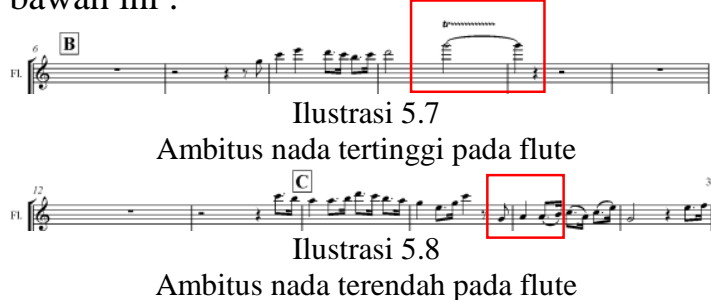

Ambitus 
Oboe merupakan satu keluarga dengan alat musik tiup kayu. Timbre oboe sangat absolut, sehingga volume yang dihasilkan cukup kuat. Ambitus nada tertinggi oboe pada orkestrasi lagu Mars Unesa yaitu : Nada C pada birama terakhir, dan nada terendah pada nada $\mathrm{F}$ pada birama 3. Dapat dilihat pada ilustrasi di bawah ini:
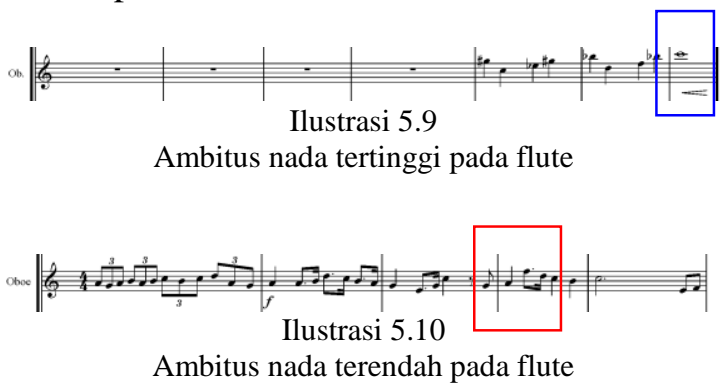

\section{Ambitus Clarinet}

Alat musik clarinet adalah alat musik transpose, yang artinya berbeda tuning dengan alat musik yang lain. Clarinet yang digunakan aransemen lagu Mars Unesa yaitu clarinet in Bes, dan juga masih satu keluarga dengan alat musik tiup kayu. Ambitus nada tertinggi yaitu C natural terdapat pada birama 23, dan ambitus terendah terdapat pada nada $\mathrm{F}$ pada birama 5. Dapat dilihat pada ilustrasi di bawah ini :
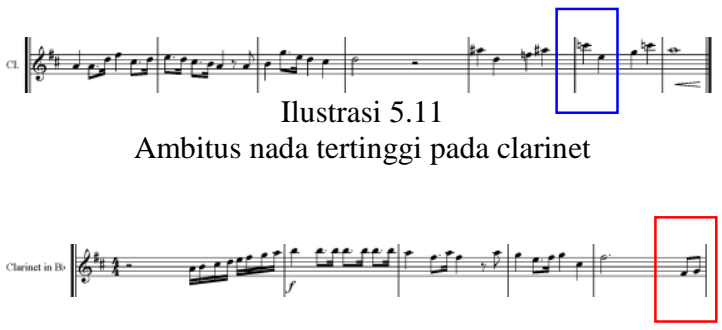

Ilustrasi 5.12

Ambitus nada terendah pada clarinet

\section{Ambitus Alto Saxophone}

Instrumen ini merupakan alat musik modern, tergabung dalam kelompok tiup logam modern. Timbre suaranya sangat berbeda sekali dengan alat musik jaman klasik. Maka dari itu, harus tepat dalam memilih nada dalam orkestrasi agar bisa harmoni dengan alat musik yang lain. Alto saxophone merupakan alat musik transpose. Ambitus nada tertinggi pada lagu Mars Unesa yaitu : nada $D$ garis bantu dua pada birama 4 , dan ambitus terendah A pada birama pertama. Dapat dilihat pada ilustrasi di bawah ini :

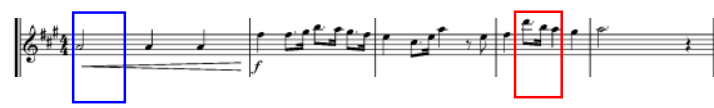

Ilustrasi 5.13

Ambitus nada terendah pada alto saxophone (garis biru) dan tertinggi (garis merah)

\section{Ambitus Tenor Saxophone}

Tenor saxophone masih merupakan keluarga dari alto saxophone dengan transpose yang berbeda, yaitu tiup logam. Instrumen ini menyeimbangkan karakter suara alto saxophone dengan range nada yang lebih rendah. Pada aransemen lagu Mars Unesa, karakter instrument ini memberikan sentuhan karakter pop modern. Ambitus nada tertinggi yang pada orkestrasi lagu ini, yaitu nada D pada birama 5, dan ambitus terendah pada nada $\mathrm{F}$ pada birama 8. Dapat dilihat pada ilustrasi di bawah ini :

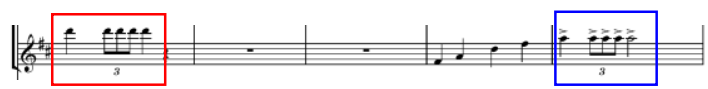

Ilustrasi 5.14

Ambitus nada terendah pada Tenor saxophone (garis biru) dan tertinggi (garis merah)

\section{Ambitus Horn}

Alat musik horn merupakan alat musik transpose, yang artinya berbeda tuning dengan alat musik yang lain, jika instrumen piano di tangga nada $\mathrm{C}$ major, maka di alat musik ini di tangga nada G. Horn yang digunakan aransemen lagu Mars Unesa yaitu horn in F. Ambitus nada tertinggi yaitu D terdapat pada birama 11, dan ambitus terendah pada nada B pada birama 3. Dapat dilihat pada ilustrasi di bawah in

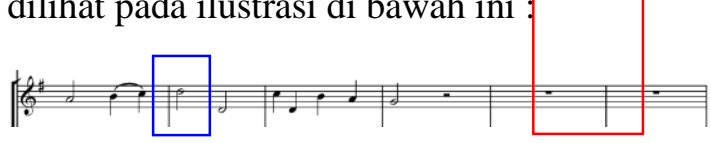

Ilustrasi 5.15

Ambitus nada tertinggi pada horn

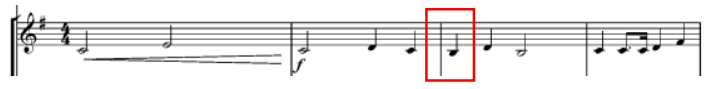

Ilustrasi 5.16

Ambitus nada terendah pada horn

\section{Ambitus Trumpet}

Pada orkestrasi lagu Mars Unesa, instrumen trumpet merupakan alat musik brass yang identik dengan musik Mars. Pemilihan instrumen ini sangat tepat untuk jenis lagu Mars yang mempunyai ciri khas musik 
militer. Trumpet juga tergolong alat musik transpose. Pada orkestrasi ini yang dipilih trumpet in Bes. Ambitus nada tertinggi pada nada A birama 19, dan ambitus nada terendah terdapat pada nada D dalam birama 8 . Hal tersebut dapat dilihat pada ilustrasi di bawah ini :

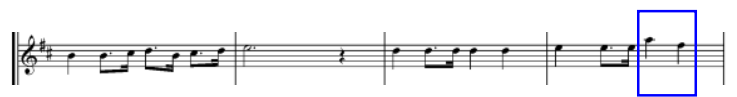

Ilustrasi 5.17

Ambitus nada tertinggi pada trumpet

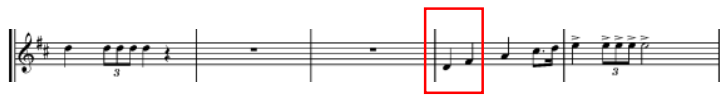

Ilustrasi 5.18

Ambitus nada terendah pada trumpet

\section{Ambitus Trombone}

Pada orkestrasi lagu Mars Unesa, instrumen trombone merupakan alat musik brass yang identik dengan musik Mars sebagai pendamping instrument trumpet. Instrumen ini sangat tepat untuk jenis lagu Mars yang mempunyai ciri khas musik militer. Trombone alat musik normal akan tetapi berbeda tanda kunci $\mathrm{F}$, karena tergolong dalam wilayah nada tengah dan bass atau middle low. Ambitus nada tertinggi pada nada $\mathrm{F}$ birama 23 , dan ambitus nada terendah terdapat pada nada $\mathrm{C}$ dalam birama 1. Hal tersebut dapat dilihat pada ilustrasi di bawah ini :

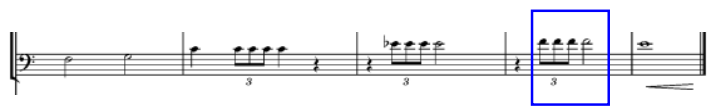

Ilustrasi 5.19

Ambitus nada tertinggi pada trombone

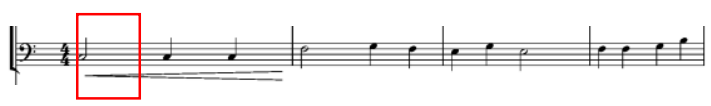

Ilustrasi 5.20

Ambitus nada terendah pada trombone

\section{Ambitus Violin}

Violin merupakan salah satu instrumen sangat penting dalam sebuah penggarapan orkestrasi. Alat musik ini tergolong dalam intrumen keluarga gesek dengan wilayah suara tertinggi atau sopran. Karakter yang dihasilkan akan terasa jika dimainkan dengan ensamble, maka akan menimbulkan karakter string yang sangat sempurna. Ambitus nada tertinggi yang dipakai pada lagu Mars Unesa yaitu nada $\mathrm{F}$ pada birama 4, dan ambitus nada terendah yaitu nada $\mathrm{C}$ pada birama 6. Dapat dilihat pada ilustrasi di bawah ini :
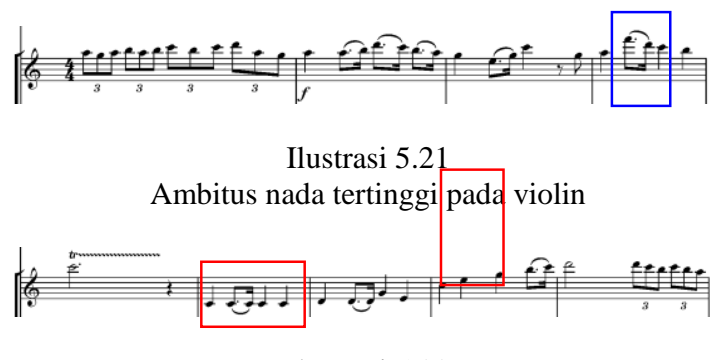

Ilustrasi 5.22

Ambitus nada terendah pada violin

\section{Ambitus Viola}

Viola adalah salah satu keluarga dalam alat musik gesek yang mempunyai wilayah nada tengah/middle. Karakter yang dihasilkan akan terasa jika dimainkan dengan ensamble, maka akan menimbulkan karakter string yang sangat sempurna jika digabungkan dengan violin, cello dan kontrabas. Ambitus nada tertinggi yang dipakai pada lagu Mars Unesa yaitu nada $\mathrm{E}$ pada birama 16, dan ambitus nada terendah yaitu nada Es pada birama 22. Dapat dilihat pada ilustrasi di bawah ini :

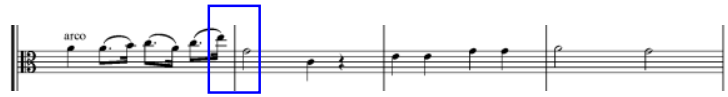

Ilustrasi 5.23

Ambitus nada tertinggi pada viola

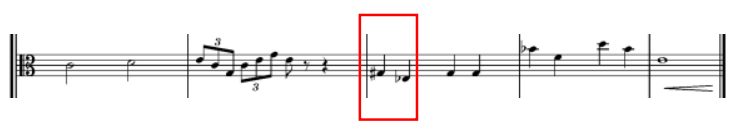

Ilustrasi 5.24

Ambitus nada terendah pada viola

\section{Ambitus Cello}

Cello juga merupakan salah satu keluarga dalam alat musik gesek yang mempunyai wilayah nada tengah bass/middle low. Insturmen ini merupakan penguhubung nada tengah dengan bass. Dalam sebuah penggarapan komposisi musik orchestra, cello merupakan variasi dalam wilayah suara bass. Ambitus nada tertinggi yang dipakai pada lagu Mars Unesa yaitu nada G pada birama 2, dan ambitus nada terendah yaitu nada $F$ pada birama 16. Dapat dilihat pada ilustrasi di bawah ini : 


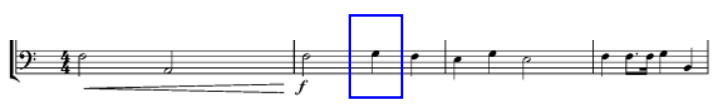

Ilustrasi 5.25

Ambitus nada tertinggi pada cello

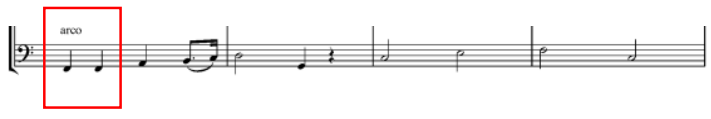

Ilustrasi 5.26

Ambitus nada terendah pada cello

Kontrabass pada orkestrasi lagu ini mempunyai pola melodi dan ritme sama dengan instrumen cello, hanya saja turun satu oktaf di bawah cello. Ambitus nada kontrabas lebih rendah satu oktaf dibanding cello, alhasil karakter yang ditimbulkan instrument tersebut yaitu bass (Low).

PENUTUP

Artikel ini menghasilkan alternative analisis musik yang sesuai dengan disiplin ilmu musik secara konvensional. Hasil penelitian menunjukkan terdapat 16 birama dengan pemilahan frase lagu dan motif. Lagu Mars Unesa menggunakan tempo gracia denga sukat birama 4/4 dengan cira khas lagu Mars yang tegas dan semangat. Pembahasan di atas merupakan analisis musik secara konvensional yang menghasilkan konsep analisis bagian dari bentuk musik yang disajikan sesuai dengan materi tema dan pokok lagu yang disajikan.

Ambitus nada pada orkestrasi pada lagu Mars ini meliputi : konsep orkestrasi, aransemen, pengembangan variasi komposisi lagu. Komposisi instrumen dalam aransemen lagu tersebut membawa dampak yang signifikan terhadap kualitas hasil aransemen yang dibuat oleh arranger. Ambitus, timbre dan tone colour yang dihasilkan oleh masingmasing instrumen memberikan kesan yang berbeda. Tema lagu mars yang bersifat riang terbawa dalam alunan melodi iringan yang disajikan dalam bentuk orkestrasi yang menarik, kreatif, dan berkarakter dalam penyajiannnya.

\section{DAFTAR PUSTAKA}

Banoe, Pono. 2003._Pengantar Pengetahuan Harmoni. Yogyakarta: Kanisius

Copland, Aaron. 1939. What to Listen for in Music. MCGraw-Hill Book Company: USA.
Isfanhari, Musafir dan Nugroho, Widyo. Pengetahuan Dasar Musik. Surabaya : Dinas P dan K Propinsi Daerah Tingkat I Jawa Timur

Kusumawati, Heny. 2008. Orkestrasi.Yogyakarta; PHKI

Moleong J, Rexy. 2010. Metodologi Penelitian Kualitatif. Bandung: PT Remaja ROSDA

Ngurah, Budi.1988. Orkestrasi, Yogyakarta: Institut Seni Indonesia press

Nettle Bruno.1984. Theory and Method in Ethnomusikology. London: The Free Press of Glencoe-Macmillan Limited

Prier, Karl-Edmund. 1991. Ilmu Bentuk Musik. Yogyakarta: Pusat Musik Liturgi

Prier, Karl-Edmund. 2009. Ilmu HarmoniEdisi Baru. Yogyakarta: Pusat Musik Liturgi

Prier, Karl-Edmund. 2011. Kamus Musik. Yogyakarta: Pusat Musik Liturgi

Percy A. Scholes. 1938. Arrangement or Transcription, Tenth Edition, Oxford . London: University Press

Siegmeister, Elle. 1965. A workbook for Harmony and Melody, Vol.1. Wadsworth Publishing Company.

Sugiyono, 2013, Metodelogi Penelitian Kuantitatif, Kualitatif Dan R\&D. (Bandung: ALFABETA) 